\title{
Cytoprotective and Antioxidants in Peroxisomal Neurodegenerative Diseases ${ }^{\dagger}$
}

\author{
Mustapha Cherkaoui-Malki 1,2,*, Saad Shaaban ${ }^{3,4}$, Mounia Tahri-Joutey 1,2,5, Ahmed Elshobaky 2,6, \\ Fatima-Ezzahra Saih 1,2,5, Dominique Vervandier-Fasseur 1,7, Claus Jacob 1,8, Boubker Nasser 1,5, \\ Norbert Latruffe 1,2 and Pierre Andreoletti 1,2 \\ 1 NutRedOx Network (COST Action CA16112), 1050 Brussels, Belgium; mouniajoutey@gmail.com (M.T.-J.); \\ f.z.saih@hotmail.com (F.-E.S.); dominique.vervandier-fasseur@u-bourgogne.fr (D.V.-F.); c.jacob@mx.uni- \\ saarland.de (C.J.); boubker_nasser@hotmail.com (B.N.); Norbert.Latruffe@u-bourgogne.fr (N.L.); \\ pierre.andreoletti@u-bourgogne.fr (P.A.) \\ 2 BioPeroxIL laboratory, Université de Bourgogne-Franche Comté, 6, Boulevard Gabriel, \\ 21000 Dijon, France; dshobaky84@yahoo.com \\ 3 Organic Chemistry Division, Department of Chemistry, Faculty of Science, Mansoura University, \\ El-Gomhorya Street, 35516 Mansoura, Egypt; dr_saad_chem@mans.edu.eg \\ 4 Institute of Organic Chemistry and Chemical Biology, Goethe-University Frankfurt, Max-von-Laue-Str. 7, \\ 60438 Frankfurt/Main, Germany \\ 5 Laboratoire de Biochimie et Neurosciences, Faculté des Sciences et Techniques, Université Hassan I, BP577, \\ 26000 Settat, Morocco \\ 6 Botany Department, Faculty of Science, Mansoura University, 35516 Mansoura, Egypt \\ 7 Institut de Chimie Moléculaire de l'Université de Bourgogne-Franche Comté, UMR6302, CNRS, \\ Université Bourgogne Franche Comté, F-21000 Dijon, France \\ 8 Division of Bioorganic Chemistry, School of Pharmacy, Saarland University, Campus B2 1, \\ D-66123 Saarbuecken, Germany \\ * Correspondence: malki@u-bourgogne.fr; Tel.: +333-8039-6205 \\ + Presented at the Natural Products and the Hallmarks of Chronic Diseases-COST Action 16112, \\ Luxemburg, 25-27 March 2019.
}

Published: 28 April 2019

Keywords: antioxidant; leukodystrophy; organoselenides; peroxisome; resveratrol

Several of the peroxisomal neurodegenerative disorders are the consequence of a specific deficiency of an enzyme or a transporter involved in peroxisomal beta-oxidation of very long chain fatty acids $[1,2]$. One of the hallmarks in these peroxisomal rare neurodegenerative diseases and in other common demyelinating disorders is the accompanying oxidative damage and neuroinflammation [3]. Compelling data indicates that oxidative stress can activate microglia leading to the overproduction of pro-inflammatory molecules [4,5]. Thus, targeting oxidative stress to limit neuroinflammation may open a new pharmacological therapy window for these still incurable devastating peroxisomal diseases. Here, we present different natural (resveratrol) [6] and synthetic (organoselenides) [7] antioxidant compounds for their capacity of scavenging oxidative stress and in the perspective therapeutic use against oxidative damage in peroxisomal disorders.

Acknowledgments: This abstract and the oral presentation are based upon work from COST Action NutRedOxCA16112 supported by COST (European Cooperation in Science and Technology). The "Ministère des Affaires Etrangères: the Embassy of France in Egypt-Institut Français en Egypte" and the "Science and Technology Development Fund" by according to a postdoctoral fellowships to S. Shaaban and to A. El-shobaky. This work was also supported by the PHC Volubilis/Toubkal program of the Comite Mixte Inter-universitaire FrancoMarocain (CMIFM, MA/14/310 and TBK 19/92-CAMPUS: 41501RJ).

Conflicts of Interest: The authors declare no conflict of interest. 


\section{References}

1. Wanders, R.J. Metabolic functions of peroxisomes in health and disease. Biochimie 2014, 98, 36-44.

2. Trompier, D.; Vejux, A.; Zarrouk, A.; Gondcaille, C.; Geillon, F.; Nury, T.; Savary, S.; Lizard, G. Brain peroxisomes. Biochimie 2014, 98, 102-110.

3. Singh, I.; Pujol, A. Pathomechanisms underlying X-adrenoleukodystrophy: A three-hit hypothesis. Brain Pathol. 2010, 20, 838-844.

4. Raas, Q.; Saih, F.-E.; Gondcaille, C.; Trompier, D.; Hamon, Y.; Leoni, V.; Caccia, C.; Nasser, B.; Jadot, M.; Ménétrier, F.; et al. A microglial cell model for acyl-CoA oxidase 1 deficiency. Biochim. Biophys. Acta Mol. Cell Biol. Lipids 2019, 1864, 567-576.

5. Raas, Q.; Gondcaille, C.; Hamon, Y.; Leoni, V.; Caccia, C.; Ménétrier, F.; Lizard, G.; Trompier, D.; Savary, S. CRISPR/Cas9-mediated knockout of Abcd1 and Abcd2 genes in BV-2 cells: Novel microglial models for Xlinked Adrenoleukodystrophy. Biochim. Biophys. Acta Mol. Cell Biol. Lipids 2019, 1864, 704-714.

6. Latruffe, N.; Lançon, A.; Frazzi, R.; Aires, V.; Delmas, D.; Michaille, J.-J.; Djouadi, F.; Bastin, J.; CherkaouiMalki, M. Exploring new ways of regulation by resveratrol involving miRNAs, with emphasis on inflammation. Ann. N. Y. Acad. Sci. 2015, 1348, 97-106.

7. Shaaban, S.; Vervandier-Fasseur, D.; Andreoletti, P.; Zarrouk, A.; Richard, P.; Negm, A.; Manolikakes, G.; Jacob, C.; Cherkaoui-Malki, M. Cytoprotective and antioxidant properties of organic selenides for the myelin-forming cells, oligodendrocytes. Bioorg. Chem. 2018, 80, 43-56.

(C) 2019 by the authors. Licensee MDPI, Basel, Switzerland. This article is an open access article distributed under the terms and conditions of the Creative Commons Attribution (CC BY) license (http://creativecommons.org/licenses/by/4.0/). 